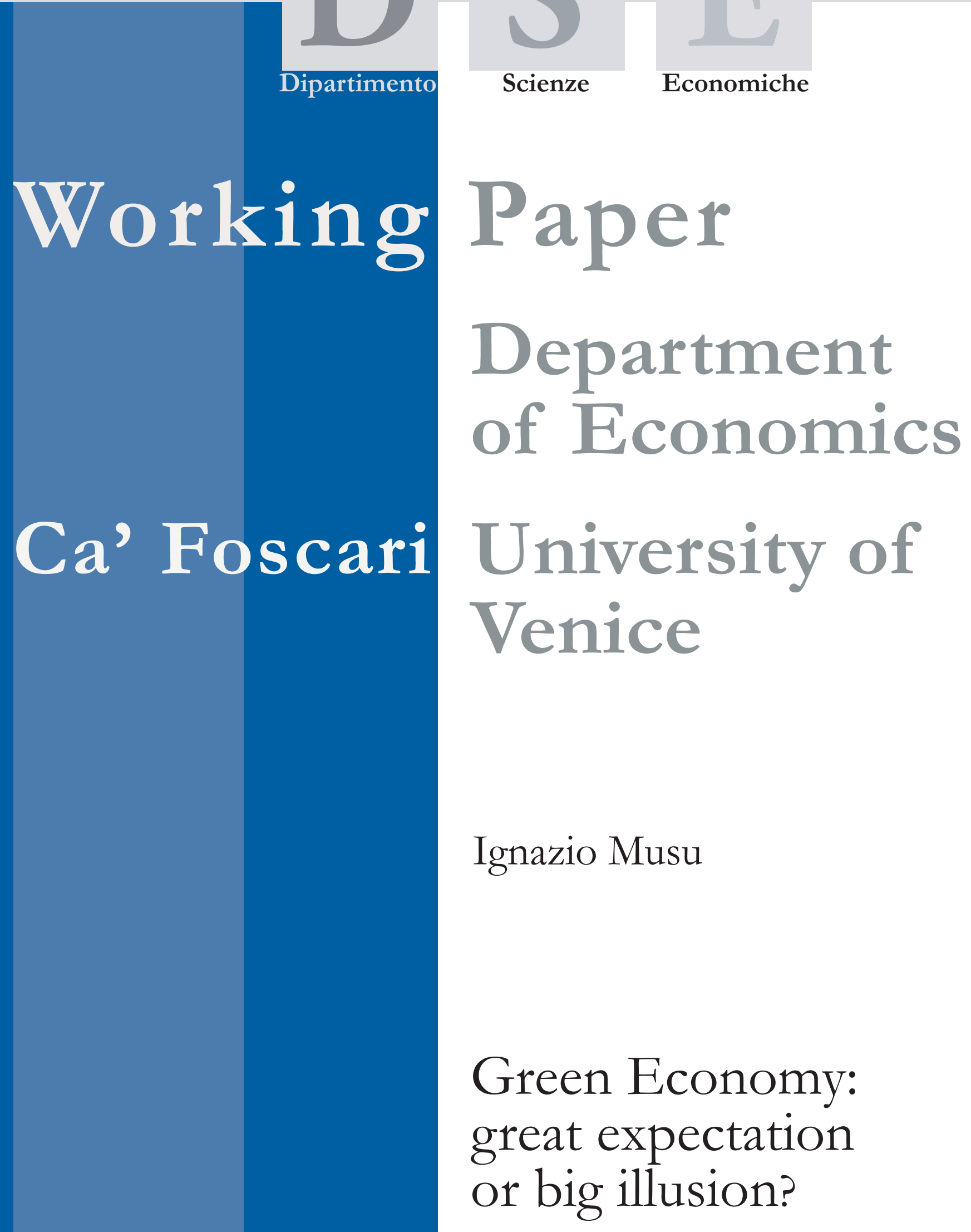




\title{
Green Economy: great expectation or big illusion?
}

\author{
Ignazio Musu \\ Università Ca' Foscari Venezia
}

First Draft: data

\begin{abstract}
Simple growth accounting shows that the negative scale effect of economic growth on the environment can be compensated by a composition effect, increasing the weight of less polluting productions, and by a technical progress favorable to the environment, in order to make possible a sustainable growth path. To achieve this result a combination of environmental regulation and innovation policy is required. Revenues from economic instruments of environmental regulation can be earmarked to environmental friendly innovations; difficulties arise because of the trade off with using those revenues as redistributive means to compensate the usually regressive nature of environmental regulation. The "case study" of the energy and climate program of President Obama is an example of the complexity of the challenge to move towards the target of a "green economy". A complementary essential role of social environmental responsibility both of consumers and firms is required.
\end{abstract}

\section{Keywords}

Economic Development, Innovation, Environmental Policies, Sustainable Development

\section{JEL Codes}

O11, O38, Q56

Address for correspondence:

Ignazio Musu

Department of Economics

Ca’ Foscari University of Venice Cannaregio 873, Fondamenta S.Giobbe 30121 Venezia - Italy

P Phone: (++39) 0412349151

Fax: (++39) 0412349210 musu@unive.it

This Working Paper is published under the auspices of the Department of Economics of the Ca' Foscari University of Venice. Opinions expressed herein are those of the authors and not those of the Department. The Working Paper series is designed to divulge preliminary or incomplete work, circulated to favour discussion and comments. Citation of this paper should consider its provisional character. 


\section{Greening the economy: pessimists versus optimists}

It is a debated question whether or not "greening" the recovery programs designed to overcome the global economic crisis is an appropriate and convenient strategy. Some believe that the economic recovery should not be constrained by any concern for the environment; environmental problems should be left totally aside and only taken in consideration once the economy had started growing again. Others believe the opposite: directing the economy recovery along "greener" guidelines will not only help the recovery itself to be successful, but it will also achieve the long run objective of promoting a model of sustainable economic development, a model of economic growth compatible with preserving and possibly improving the environmental quality.

This second vision seems more convincing. The first one considers the environmental quality as a luxury good, ignoring the existence of structural environmental problems threatening the sustainability of the economy and of the society in the long run.

However the target implied by the second vision should not be considered as something that will be automatically realized, but as an opportunity that must be pursued with appropriate policies. The risk must be avoided of wishful declarations, not followed by any concrete initiative.

In what follows I will try to show that "Greening the economy", which is a different way of expressing the objective of achieving a model of sustainable economic development, requires a set of strong interactive and complementary conditions, not easily realized: environmental regulation, environmental innovation policy and environmental responsibility of consumers and firms.

\section{Some accounting on the relation between environment and economic growth}

Sustainable economic growth requires a balance between the environmental impact of the economic growth and the assimilative capacity of the environment. An index of the environmental impact are polluting emissions, e.g. emissions of $\mathrm{CO} 2$ and other greenhouse gases in the case of the problem of climate change.

If the environmental quality has achieved an acceptable level which must at least be maintained, the flow of polluting emissions in the environment should remain within the assimilative capacity. If the environmental quality must be improved, the flow of polluting emissions must decline over time. In the case of the climate change, it is clear that the concentration of $\mathrm{CO} 2$ in the atmosphere should be reduced; hence the flow of emissions of $\mathrm{CO} 2$ at the world level must decline over time. 
The pressure of economic activity on the environment depends on three factors (Brock and Taylor, 2005): a) growth of the scale of the economic system (scale effect); b) changes in the productive structure (composition effect); c) how technological development affects the impact of the economic activities on the environment (technique effect).

The scale of the economy grows because of population growth and of growth in output per capita. The effect of these factors on the environment, when they are considered alone, is negative: hence the scale effect is negative.

The negative scale effect may be compensated or more than compensated by a reduction in the average aggregate coefficient of environmental impact per unit of GDP. If this coefficient declines at a rate greater than the rate at which GDP grows, the environmental impact declines. In the case of climate change, the emission flow of $\mathrm{CO} 2$ must decline over time: this requires that the average coefficient of emissions per unit of output declines at a rate higher that the rate of GDP growth.

The dynamics of the aggregate coefficient of emissions per unit of GDP depends on two factors: a) the economic structure; b) the dynamics of the coefficients of emissions per unit of output in each productive sector.

The higher is the weight of the sectors whose emission coefficient per unit of output is declining faster, the more rapidly will the aggregate emission coefficient per unit of GDP decline, and the higher is the likelihood that the composition and technique effect overcome the scale effect.

Changes in the productive structure basically depend on the evolution of the final demand composition: hence a positive effect of the dynamics of aggregate emissions will come from an evolution of the consumption pattern towards goods whose production and consumption entails lower emission coefficients (positive composition effect).

The dynamics of emission coefficients in the individual sectors reflects the dynamics of technological progress in each sector. A positive effect is expected to come from a technological progress reducing these emission coefficients. However, technological progress also increases labor productivity. This increases output per capita and hence contributes to the negative scale effect. Thus, there is an intrinsic ambiguity in the role of technological progress for a sustainable economic growth.

A technological progress "good" with respect to sustainability shows up as reduction of emission coefficients per unit of output in individual sectors; a technological progress "bad" with respect to sustainability shows up in labor 
productivity growth. The net "technique" effect will be positive for sustainable economic growth if the "good" type of technological progress prevails over the "bad" type. The optimal situation would be to have an elasticity of the emission coefficient per unit of output with respect to the output per capita higher than one in absolute value.

The interaction between different factors affecting the dynamics of the emission flow turns out to be very complex; various configurations in the relation between environment and economic growth can emerge from this interaction. It is not automatic that the prevailing one is that which allows a combination of a positive composition and technique effects larger than a negative scale effect. The spontaneous market behavior is not sufficient; policies are required.

\section{Environmental regulation and environmental innovation}

Environmental regulation plays an important role in achieving a sustainable economic growth. Even the optimistic vision expressed by the Environmental Kuznets Curve (Borghesi and Vercelli, 2008) recognizes the importance of the role of environmental regulation in affecting the moment where the curve will start declining.

By increasing the price of the emissions, according to their marginal social damage, the economic environmental regulation provides an incentive to adjust the way economic agents behave in a direction more favorable to the environment. Consumers' demand should shift to more environmental friendly products. Firms should modify their productive processes and products towards features reducing emissions per unit of output. Hence the economic environmental regulation is expected to favor: a) a positive composition effect; $b$ ) a positive net technique effect.

The positive effect of the economic environmental regulation acts through the price effect and what we can called "the Porter effect". According to the price effect, if polluting emissions are considered as a productive input; a higher price of this input, determined by an economic environmental regulation, is an incentive towards an "induced innovation" (Hicks, 1932) saving this input. According to the "Porter effect" (Porter and van der Linde, 1995) environmental rules induce firms to adjust their strategy so as to discover new opportunities for efficiency and profit perspectives' improvement offered by environmental protection.

However it is not always the case that the environmental regulation succeeds in stimulating environmental friendly innovations in the productive processes and in the outputs' features. Often the effect of the environmental regulation is simply 
to increase expenditures in emission abatement, aiming at reducing end-of pipe emissions, without affecting the nature of productive processes and outputs.

In order to induce an environment oriented innovation, the environmental regulation should be able to move firms to a longer run strategy. Environmental regulation should be consistent and persistent over time in order to send the appropriate signals inducing firms to innovate: in other words, firms should be convinced that it is in their interest to undertake environmental innovations in order to reduce the higher expected costs of a future stricter regulation.

Very important is the diffusion of the environmental regulation at an international scale. This process widens the market for new environmental technologies, not only for production technologies but also for products using those technologies and thereby reducing the environmental impact of their consumption. This market effect is very important in convincing firms to undertake environment friendly innovations.

The literature agrees in recognizing that an economic environmental regulation (either as emission taxes or as tradable emission permits) is successful in inducing the adoption of environment friendly existing technologies (Newell, Jaffe and Stavins, 2006; Popp, Newell and Jaffe, 2009). But what about the effect on research for the discovering of new technologies?

An important distinction is between "incremental" and "radical" innovations. The first are innovations within an existing technological regime; the second modify the existing technological regime. Radical innovations require relevant investments in research and their market success is more uncertain.

In the energy field, incremental innovations are those improving energy efficiency of the existing fossil fuels, whilst radical innovations develop alternative technologies to those based upon fossil fuels. The second requires higher investments, of longer duration, with riskier market perspectives.

\section{Combining environmental and innovation policies}

The thesis prevailing in the literature is that environmental regulation is successful in promoting incremental innovations, but not successful enough in promoting radical innovations. This is not surprising as radical environmental innovations are characterized by very high market risks, so that firms are very careful in undertaking them. The message is that for promoting radical environmental innovations, environmental regulation should be integrated with a specific policy for the promotion of the required technological innovation. 
Carraro and Siniscalco (1994) were among the first to show that economic instruments of environmental policy should be associated to the traditional instruments of industrial policy to achieve an optimal level of emission reduction. Later, similar results have been obtained for the more specific problem of promoting technological innovation to reduce $\mathrm{CO} 2$ emissions to mitigate the climate change (Gillligham, Newell and Pizer, 2006; Popp, 2006; Otto, Loescher and Reilly, 2006; Popp, Newell and Jaffe, 2009).

This same type of result has been obtained within models of endogenous technological progress. Using a Romer type model of endogenous technical progress, Van Zon and Yetkiner (2003) show that an energy tax recycled as a subsidy to research increases the long rate of endogenous growth. Gerlagh, Kverndokk and Rosendal (2009) obtain the same result within a model with expanding variety endogenous technical progress. Grimaud and Rouge (2008) confirm this result in a model of endogenous growth using the concept of "directed technological change" introduced by Acemoglu (2002).

Acemoglu, Aghion, Bursztyn and Hemous (2009) use a production function, formerly used by Sue Wing (2006), where a final output is produced by two intermediate inputs, one "clean" and the other "dirty", each obtained by machines and labor. The "clean" sector uses machines whose operation is not damaging the environment, the "dirty" sector uses machines whose operation is negative for the environment. The two intermediate inputs can be substituted in producing the final output, with a constant elasticity of substitution. This elasticity of substitution is assumed to be sufficiently high.

Innovation is machine quality improving. The present state of technology is represented by the average productivity of the existing machines: it reflects the past accumulated innovations, and these are assumed to be higher in the dirty sector because in this sector the innovations have been accumulated over a longer time period than in the clean sector, where they are more recent.

The incentive to innovate is higher where the average productivity of machines is higher, hence in the dirty sector. According to the approach of directed technological change, the innovation is also directed where the market is wider. This market effect is determined by the ratio between average sectoral productivities and by the elasticity of substitution between the intermediate inputs. The higher is the elasticity of substitution, the more the innovation is favored in the sector whose relative average productivity is higher, hence in the dirty sector.

The price of the intermediate input produced with more productive machines (the dirty one) will be relatively lower. As a price effect favors innovation in the sector where the relative price is higher, this means that the price effect will favor 
innovation in the clean sector. Only when the elasticity of substitution is low enough, the price effect dominates and clean innovation is favored. The implication of assuming an elasticity of substitution sufficiently high is that the market forces are likely to promote innovations in the dirty sector, and policies are required to correct this trend.

An environmental policy is required. For example in the climate change problem, a "carbon tax" discouraging dirty innovation and production is recommended. However, in order to avoid an excessive use of "carbon tax" which would eventually discourage production and growth, an optimal policy involves both "carbon taxes" and research subsidies. In other words, environmental regulation acts through reducing the production of the polluting intermediate input; to promote innovation in the clean sector, a specific innovation policy is needed to increase the ratio between the productivity level in the clean sector relatively to the dirty sector.

Acemoglu, Aghion, Bursztyn and Hemous (2009) also show that implementing and combining the two policies only in advanced economies is not enough in an international framework where technologies developed in advanced economies can be imitated and transferred to developing economies. This is due to a "pollution haven" effect (Copeland and Scott Taylor, 2003; Di Maria and Smulders, 2004) which induces the delocalization of dirty activities in developing countries without an environmental regulation in these countries.

The existing literature agrees in suggesting the need of linking environmental regulation to an environmental innovation policy. One way to do it is to use the revenues from the economic instruments of the environmental regulation to finance, at least partly, the innovation policy: in the direct form of promoting an environmentally oriented public expenditure, or in the indirect form of subsidizing the environmental research of private firms. This possibility is immediately seen if emission taxes are used; in the case of tradable emission permits, they should initially auctioned in order to provide a revenue to the auctioning authority.

However, using the revenues from the economic instruments of environmental regulation to sustain a public policy of environmental innovation is not easy. There is trade off between this type of utilization of the revenue and an alternative one, consisting in using the revenue to compensate those who are more heavily hit by a typically regressive type of fiscal policy as that represented by the economic instruments of environmental regulation.

Using the revenues of the economic instruments of environmental regulation for redistributive policies is highly demanded in any society. The problem is how to implement these redistributive policies in a way that does not neutralize the 
environmental direction of the economic agents' choices induced by the environmental regulation.

But even if this is the case, a trade off remains between the two ways to utilize the revenues from the economic instruments of environmental policy: redistribution and incentive to innovation.

\section{The program of President Obama: an attempt in the right direction}

An interesting attempt to integrate environmental regulation and environmental innovation policy is represented by the program of President Obama on energy and environment included in the American Clean Energy and Security Act (ACES), which was approved at the end of June 2009 by the US House of Representatives with a small majority of seven votes.

A debate on an energy and climate change act is currently taking place in the US Senate; as it may end out to be different from the act approved in the House of Representative, I will concentrate on this one.

A first objective of the ACES act is to increase the energy efficiency of the American system and to promote structural changes in the energy demand. The primary energy requirements should be reduced by $7 \%$ in 2020 and by $12 \%$ in 2050; according to the Environment Protection Agency (EPA, 2009), the share of primary energy of the "low or zero-carbon type" will increase to $18 \%$ in 2020 and to $38 \%$ in 2050 with respect to the "Business as Usual" share of $14 \%$.

A second related objective of the ACES act is to reduce within 2020 the flow of CO2 emissions by 17\% with respect to the 2005 level; within 2050 these emissions should be 83\% lower than those in 2005.

The main economic instrument to achieve this objective is a system of tradable emission permits of the "cap and trade" type. $85 \%$ of these permits will be initially distributed freely to firms, and the remaining $15 \%$ will be auctioned. The share of auctioned permits will increase up to $70 \%$ in 2030.

The method used in the initial allocation of permits does not modify the environmental effects of the instrument: polluting firms are facing the same emission costs in both cases, auctioned or free initial allocation; hence their decisions on how to reduce emissions do not depend on the method of initial allocation.

Where the difference between methods of allocation is important lies in the possibility of undertaking related policies. A low amount of auctioned permits 
will not provide sufficient revenues to be used either as a tool of redistributive policy to compensate those negatively affected by higher energy costs, or to support policies for environmental innovation.

The ACES act is definitely concerned with the redistributive issue. Robert Stavins suggests that the best way to assess the implication of the bill is not by opposing "free allocation" to "auction", but by founding "the ultimate beneficiary of each element of the allocation and auction, that is, how the value of the allowances is allocated". He finds that over the entire period from 2012 to 2050 consumers and public purposes will benefit for $80 \%$, while private industry will benefit for $20 \%$ (Stavins, 2009a).

Compensating households for the regressive effects of an increase in energy prices is a difficult task. Permits allocated freely to local utilities for distributing electric energy and gas will be given under the constraint that households' wealth is in someway protected from the effect of higher energy prices. As noted before, the way this compensation will take place should discourage energy demand. Hence it should not take place through a tariff reduction, but through lump sum transfers of rebates, which will not affect the incentives which higher relative energy prices represent towards energy saving and efficiency.

In the bill, the allocation of permits to firms is also oriented to promote a gradual development of new technologies with a lower energy impact and using renewable energy sources.

The contribution of US to the global climate change problem must be a joint contribution with the largest possible number of other countries of the world. As in any typical public good problem, each potential contributor to the provision of the global public good represented by climate improvement fears the risk of being excessively damaged by the "free riding" behavior of the others potential contributions. The US fear that any unilateral action to reduce CO2 emissions could damage the competitiveness of the industrial American system with respect to other "big emitters" such as China and India, that could not undertake similar measures.

This concern is reflected in two points of ACES act. The first one is found at the beginning of the text, where "international participation" is being defined: it prescribes that the Environmental Protection Agency must yearly report to the Congress on whether or not China and India have adopted CO2 emission reduction standards similar to those adopted in the ACES act. If this is not the case, EPA is required not only to inform the Congress, but to inform the public opinion through an appropriate use of the "media". 
The second point concerns the measure of assigning a share of the freely allocated emission permits to some energy intensive sectors highly sensible to international trade (aluminum, cement, iron and steel). This subsidy to polluting production is justified as a measure to preserve international competitiveness, by avoiding "carbon leakage", which shifts comparative advantage of producing carbon-intensive goods in the direction of countries not imposing the same cost on the production of those goods as imposed in US. This measure is combined with the parallel measure of associating emission permits to the imports of carbon-intensive goods from countries not undertaking climate policies of the same type of the American policies.

As noted by Stavins (2009b) it is questionable whether such a measure, which corresponds to a "border tax", will succeed as an incentive for developing countries with high CO2 emissions to impose domestic costs on those emissions in order to avoid the border tax. Stavins observes that China only exports 3\% of its cement production and he rightly doubts that China would be willing to increase the domestic cost of producing almost the whole cement to protect less than $3 \%$ of its production.

The ACES act clearly shows that the US are prepared to undertake domestic measures to mitigate $\mathrm{CO} 2$ emissions, but that they would make these decisions conditional to similar policies by other "big emitters". The circular problem emerging from such an attitude is well known in the theory on international environmental agreements (Barrett, 2003): the US constrain their strategy in favor of climate change mitigation to a cooperative answer by "big emitters" like China, India and other large emerging developing countries; but the probability that these countries accept to join a cooperative mitigation policy depends on the credibility of the position of the US.

Considered in this perspective, the Copenhagen Agreement, although it appears rather general and unfortunately lacking some more precise quantitative emission reduction commitments, can be seen as a first step forward in the direction of building a more cooperative strategy involving both types of "big emitters", advanced economies such as US and EU, and developing emerging economies such China and India. It is important that the agreement was initially proposed and signed by US, China, Brazil and South Africa; as it is important that the principle of "common but differentiated responsibilities" was recognized, so that each nation, including the rapidly growing developing countries which are parts of the so-called Non-Annex I countries according to the Kyoto Protocol terminology, accepts a commitment to a domestic climate policies which will be assessed through some kind of international consultation and analysis.

If the US could succeed in having a law (passed also by the Senate) committing the country to a consistent strategy not only to address the domestic energy 
challenge, but also the way the US economy could contribute to the global climate change problem, this would be a further step towards the conditions required to build an effective international post-Kyoto agreement. The US (together with the EU) would give an example to emerging rapidly developing countries, and they would be more credible in requiring these countries to undertake similar mitigation actions.

\section{Environmental social responsibility: an additional pillar for a green economy}

Although the distributive concern seems to be prevailing over the need of devoting sufficient resources to an environmental innovation policy, the ACES act is an important step towards the integration of environmental regulation with an environmental innovation policy.

But it is also an example of how difficult this integration is; moreover it shows that such an integration may not be sufficient for building a green economy. The lacking condition is a widespread environmental responsibility of consumers and firms.

Environmentally responsible choices of consumers are the result of a greater environmental awareness of consumers which may derive both from moral factors, giving an existence value to the preservation of the environment and of the nature, and from the perception of the health risks associated to environmental deterioration.

Environmentally responsible choices of consumers may help regulation in sustaining demand and creating a wider market for environment friendly goods. If consumers show a bigger willingness to pay for cleaner products and processes relatively to dirty ones, this gives firms a clear market signal which reinforces the signal coming from environmental regulation.

Environmental responsibility of firms may also derive both from moral factors included in the ethical firm's codes and from a stronger pressure of the different stakeholders including a "watchdog effect" from the public opinion. Bad reputation and potential liability actions are among the most important drivers of voluntary strategies undertaken by firms to improve their environmental performance.

There are signs that the practical environmental performance of firms does not always confirm the traditional idea that "businesses...(should) behave in an unprincipled fashion to make money". "Principled behavior and profitable behavior" are not necessarily in conflict (Heal, 2008). There is increasing 
evidence that the environmental responsibility of firms is paying in terms of market success (Esty and Winston, 2006; Makower, 2009).

A widespread culture of environmental responsibility in the society supports a consensus for public choices in the direction of a sustainable economic growth: it makes environmental regulation more likely to be approved and implemented, and at the same time allows it to be less invasive.

I conclude that a complementary relation exists between environmental regulation, environmental innovation policy and environmental social responsibility: these are the three pillars supporting the hope for the building of a green economy. Making them work together is not an easy task, but being aware of the complexity of their interaction and of the factors required for their synergy to be successful is a necessary condition to avoid that "greening the economy" remains an illusion deprived of any practical opportunity of implementation. 


\section{References}

D. Acemoglu, Directed Technical Change, Review of Economic Studies, 69, 2002, pp. 781-809.

D.Acemoglu, P.Aghion, L.Bursztyn, D.Hemous, The Environment and Directed Technical Change, Mimeo, 2009.

S.Barrett, Environment and Statecraft, The Strategy of Environmental TreatyMaking, Oxford University Press, Oxford, 2003.

S.Borghesi, A.Vercelli, Global Sustainability, Social and Environmental Conditions, Palgrave Macmillan, New York, 2008

W. Brock, M. Scott Taylor, Economic Growth and the Environment: A Review of Theory and Empirics, in P.Aghion, S.Durlauf, Handbook of Economic Growth, IB, Elsevier, Amsterdam, 2005, pp. 1749-1821.

C.Carraro, D. Siniscalco, Environmental Policy Reconsidered: the Role of Technology Innovation, European Economic Review, 38, pp. 545-555.

B.Copeland, M.Scott Taylor, Trade and Environment, Princeton University Press, Princeton, 2003.

C.Di Maria, S.Smulders, Trade Pessimists vs Technology Optimists: Induced Technical Change and Pollution Havens, Advances in Economic Analysis \& Policy, 4, 2004, pp.1-25.

EPA, Analysis of the American Clean Energy and Security Act, US Environmental Protection Agency, Office of Atmospheric Programs, 2009.

D.Esty, A.Winston, Green to Gold, Yale University Press, New Haven, 2006.

R.Gerlagh, S.Kverndokk, K.Rosendal, Optimal Timing of Climate Change Policy: Interaction between Carbon Taxes and Innovation Externalities, Environmental and Resource Economics, 43, 2009, pp. 369-390.

K. Gillingham, R. Newell, W. Pizer, Modelling Endogenous Technological Change for Climate Policy Analysis, Energy Economics, 30, pp. 2734-2753.

A. Grimaud, L. Rouge, Environment, Directed Technical Change and Economic Policy, Environmental and Resource Economics, 41, 2008, pp. 439-463. 
A.Jaffe, R.Newell, R.Stavins, A tale of two market failures: Technology and environmental policy, Ecological Economics, 54, 2005, pp. 164-174

G. Heal, When Principles Pay, Columbia University Press, New York, 2008.

J. Hicks, The Theory of Wages, Macmillan, London, 1932.

J.Makover, Strategies for the Green Economy, McGrawHill, London, 2009.

R.Newell, A.Jaffe, R.Stavins, The effects of economic and policy incentives on carbon mitigation technologies, Energy Economics, 28, 2006, pp. 563-578.

V.Otto, A. Loeschel, J. Reilly, Directed Technical Change and Climate Policy, MIT Joint Program on Science and Policy of Global Change, Report n. 134, 2006.

D. Popp, R\&D Subsidies and Climate Policy: is there a "free lunch"?, Climate Change, 77, 2006, pp. 311-341.

D. Popp, R. Newell, A. Jaffe, Energy, the Environment and Technological Change, NBER WP n. 14832, 2009.

M.Porter, C.van der Linde, Towards a New Conception of the EnvironmentCompetitiveness Relationship, Journal of Economic Perspective, 9(4), 1995, pp. 97-118

R. Stavins, The Wondeful Politics of Cap-and-Trade, Harvard Belfer Center for Science and International Affairs, Kennedy School of Governement, http://belfercenter.ksg.harvard.edu, 2009

R. Stavins, Worried about international competitiveness, Harvard Belfer Center for Science and Inter nternational Affairs, Kennedy School of Governement, http://belfercenter.ksg.harvard.edu, 2009

I.Sue Wing, Representing Induced Technological Change in Models for Climate Policy Analysis, Energy Economics, 28, 2006, pp. 539-562.

A. Van Zon, I. Yetkiner, An Endogenous Growth Model with Embodied Energysaving Technical Change, Resource and Energy Economics, 25, 2003, pp. 81103. 